\title{
INVESTIGAÇÃO SOBRE A IMPORTÂNCIA DO ESTÁGIO E DO PIBID PARA FORMAÇÃO DOCENTE DOS ALUNOS DO CURSO DE LICENCIATURA EM QUÍMICA DA FACEDI/UECE
}

José Carlos Miranda Pires*(Bolsista de Iniciação a Docência na Universidade Estadual do Ceará-UECE) Amabia Firmino Rodrigues; (Bolsista de Iniciação a Docência na Universidade Estadual do Ceará-UECE) Edinilza Maria Anastácio Feitosa; (Profa. Adj. da Universidade Estadual do Ceará-UECE) Julyane Moreira de Sousa; (Bolsista de Iniciação a Docência na Universidade Estadual do Ceará-UECE) Luiz Eduardo Torres dos Santos; (prof. da EEEP Rita Aguiar Barbosa)

Nicole Lopez da Silva Araújo; (Bolsista de Iniciação a Docência na Universidade Estadual do Ceará-

UECE)

*carlos.pires@aluno.uece.br

\section{RESUMO}

O PIBID se apresenta como uma ferramenta importante para a valorização e formação de novos professores, já que esse programa oportuniza aos alunos participantes, uma vivência do magistério desde o princípio do seu processo formativo, conhecendo e aprendendo novas metodologias de ensino, mediante observação dos docentes da escola, além de estar dia a dia em contato com os alunos. Por outro lado, os alunos do curso de Licenciatura em Química da Faculdade de educação de Itapipoca (FACEDI/UECE) experimentam no estágio supervisionado, outras oportunidades de exercitar a docência. No entanto, percebe-se que o estágio apresenta diversas limitações as quais, não são vistas no PIBID. Assim, o objetivo geral desta pesquisa foi investigar a partir da reflexão de professores da escola básica, a importância deste programa(PIBID) para a formação docente, como tem sido trabalhado o estágio supervisionado obrigatório na escola e que propostas poderiam ser sugeridas para melhorar o estágio à partir destas reflexões. Nesta pesquisa do tipo descritiva e exploratória, com abordagem qualitativa, usou-se para a coleta de dados, entrevistas aos professores do ensino básico dividindo estes últimos em dois grupos: aqueles que vivenciaram o estágio e o subprojeto e aqueles que tiveram apenas o estágio supervisionado como prática docente. Através dos dados analisados verificou-se que na concepção dos professores, o PIBID é importante na formação docente e que o estágio poderia ser muito melhor trabalhado, se bem planejado, principalmente quanto às atividades a serem realizadas na escola, com um acompanhamento mais próximo do professor regente e do professor da instituição formadora

Palavras-Chave: PIBID, Estágio Supervisionado, Formação Docente

\section{ABSTRACT}

The PIBID presents itself as an important tool to the development and training of new teachers, since this program provides an opportunity for participating students a teaching of the experience from the beginning of their formation process, knowing and learning new teaching methodologies, through observation of teachers school, besides being a daily contact with students.On the other hand, students of the Bachelor's Degree in Chemistry from education College of Itapipoca (FACEDI / UECE) experience in supervised training, other opportunities to exercise teaching.However, it is clear that the training has several limitations which are not seen in PIBID. Thus, the general objective of this research was to investigate from the reflect of basic school teachers the importance of this (PIBID) program for teacher training, as has been worked mandatory supervised practice in school and what proposals could be suggested to improve the training from these reflections. In this research descriptive and exploratory, with qualitative approach was used to collect data, interviews with basic education teachers dividing 
the latter into two groups: those who experienced the training and the subproject and those who only had supervised training as teaching practice. Through the data analyzed it was found that from the reflection of teachers, the PIBID is important in teacher training and the stage could be much better worked, if well planned, especially regarding activities to be performed at school, with an accompanying more near the regent professor and professor of educational institution.

Keywords: PIBID, Supervised Internship, Teacher training

\section{O ESTÁGI O, O PIBI D E A FORMAÇÃO DOCENTE}

A qualidade da educação depende dentre outros fatores, do educador, da sua preparação e dos subsídios dados a ele, para exercer uma prática pedagógica que contribua para a aprendizagem de seus alunos. Do mesmo modo o educando no seu papel de aprender, de se tornar protagonista do seu meio, depende das influências externas, mas principalmente das orientações e ensinamentos do seu professor, isso mostra a necessidade de quem ensina, de ter uma preparação desde a faculdade e ser capacitado para os desafios da docência. Claro que a formação continuada é essencial e determinante para uma renovação da prática pedagógica do professor, pois garante para este a oportunidade de se atualizar e atender as demandas da sala de aula.

No processo de formação, o estudante de nível superior precisa ter o contato com o meio profissional, no qual irá atuar. Na graduação, o estudante de licenciatura possui o estágio supervisionado obrigatório como intermediador para o contato inicial com a escola, para uma vivência com os alunos e, principalmente, observar o professor regente na sua atuação docente, adquirindo experiência e conhecimentos e uma visão futura da sua própria atuação.

O estágio abrange ações, como por exemplo, a observação, no qual o estagiário observa o fazer docente dos professores que já possuem a formação acadêmica e que lecionam no ensino público ou privado, a própria participação e as regências feitas, na atuação em sala de aula juntamente com o professor titular, guiados pelo planejamento antecipadamente preparado (XAVIER, 2009, p.06).

Entretanto, na prática, a realidade é outra, pois o tempo dedicado as atividades na escola é muito pequeno, e o aprendizado fica comprometido, a convivência na escola e em sala de aula não o capacita integralmente. O licenciando torna-se bem preparado enquanto aluno da faculdade, mas conclui o curso sem possuir uma dimensão ampla e crítica, ou mesmo familiarizado com o ambiente escolar.

Portanto grande parcela dos docentes se depara com dificuldades de inserção no início de suas atividades em sala de aula e na escola como o todo, sendo que enquanto estudante de licenciatura teve apenas o estágio supervisionado obrigatório como interposição ao ambiente de atuação profissional, não possuindo um contato assíduo e constante com o âmbito escolar.

Os novos professores são obrigados a se reavaliar e se adequar a sua nova realidade, o que é difícil, pois demanda tempo, paciência e força de vontade. Tais fatos poderiam não existir se enquanto licenciando tivesse uma preparação com qualidade e com maior tempo experimental. Segundo Oliveira e Barbosa (2013, p.150) a busca por uma qualidade maior no processo de ensino tem possibilitado uma ênfase maior a novas políticas de formação para os docentes brasileiros no decorrer dos anos.

Dentre essas políticas públicas está o Programa de Iniciação à docência (PIBID), que segundo Rosa e Mattos (2013, p.164), este programa em parceria com o ensino básico dos municípios e estados, proporciona o ingresso do licenciando na realidade escolar desde o princípio de sua formação. De acordo com Oliveira e Barbosa (2013, p.156) o PIBID tem se mostrado uma das metodologias de formação mais significativas nas últimas décadas, pois possibilita, especialmente no curso de licenciatura, concretizar o acesso e a continuação dos acadêmicos.

Sendo assim, deve-se avaliar as contribuições tanto dos estágios supervisionados quanto do PIBID na formação docente dos professores. Esta avaliação deve levar em conta as opiniões de sujeitos que estão diretamente ligados às duas atividades de prática docente e que atuam nas 
escolas. Dentro deste contexto, a referida pesquisa teve como propósito demostrar segundo a visão dos professores egressos do curso de Licenciatura em Química da FACEDI/UECE, se os objetivos iniciais propostos pelo o PIBID têm sido alcançados, ou seja, se este programa tem sido relevante na formação docente. Além disso, procura-se fazer uma avaliação da concepção destes sujeitos sobre o estágio supervisionado comparando-as com as concepções sobre o PIBID.

\section{MÉTODOS}

Este estudo propôs-se investigar mais detalhadamente a importância do subprojeto PIBID Química, para a formação dos alunos de Licenciatura do Curso de Química da FACEDI. Investigou-se as percepções e posicionamentos de professores que participaram do PIBID durante seu processo de formação e de professores que tiveram apenas o estágio supervisionado obrigatório como prática de iniciação à docência. Neste trabalho utilizou-se como técnica, uma pesquisa de campo definida por Marconi e Lakatos (2003, p.185) como uma forma de adquirir informações e resultados sobre um determinado problema, na busca de obter respostas sobre os questionamentos pré-determinados.

A pesquisa é do tipo descritivo-exploratória, que para Gil (2008a, p. 42),tem como uma das particularidades mais expressivas, a utilização de métodos padronizados de coleta de dados. Ainda segundo o pensamento de Gil (2002, p.41) a pesquisa exploratória consiste na maior aproximação com a temática, tornando-a mais clara, além de promover entrevistas com sujeitos que experimentaram a prática do problema proposto. O trabalho baseia-se em uma análise qualitativa, pois tal pesquisa é norteada em compreender a aplicação do subprojeto PIBID/Química, a sua contribuição, e, por conseguinte, o foco do estudo, a sua importância para a formação dos alunos de Licenciatura do curso de Química. A pesquisa qualitativa baseia-se numa conexão interrupitível entre a realidade concreta e a subjetividade do sujeito (KAUARK; MANHÃES; MEDEIROS, 2010, p.27).

Como instrumento de coleta de dados, optou-se pela entrevista destinada a dois grupos de professores: Os professores supervisores do programa PIBID, levando em consideração o fato de eles terem tido apenas o estágio como preparação para a carreira como professor, e professores também da escola básica que além do estágio tiveram a oportunidade de participarem do PIBID.

O trabalho foi constituído em quatro fases que foram fundamentais para a realização da pesquisa. Iniciou-se com a pesquisa bibliográfica, pois com o tema definido, fez-se um levantamento de trabalhos que discutiam sobre o referido tema, focando principalmente na importância do PIBID Química na formação dos alunos de Iniciação à Docência (IDs). Essa pesquisa é o primeiro passo a se fazer, sendo de fundamental importância, pois segundo Marconi e Lakatos (2003, p.185), a mesma servirá, como etapa inicial para compreender-se de forma atualizada o problema em estudo, assim como os trabalhos feitos a respeito e os posicionamentos mais relevantes sobre a temática. A pesquisa foi fundamentada em trabalhos já elaborados, composto especialmente de livros e artigos científicos Gil (2002, p.44), que tiveram participação importante na discussão dos resultados deste trabalho.

Formulou-se dois roteiros para a aplicação da entrevista. A primeira entrevista com oito perguntas foi aplicada a dois professores que tiveram a experiência do PIBID e do Estágio Supervisionado obrigatório. A segunda entrevista com sete perguntas, foi aplicada a quatro professores supervisores do subprojeto PIBID Química da FACEDI/UECE que tiveram apenas o estágio obrigatório como forma de vivenciar à docência. Segundo Gil (2008b, p.128) a entrevista é um meio no qual o entrevistador fica defronte ao entrevistado e estabelece perguntas, com o fim de obter os resultados necessários.

A entrevista realizada foi do tipo estrutural, com perguntas que seguem uma determinada temática de análise. O entrevistador questiona e o entrevistado responde (KAUARK; MANHÃES; MEDEIROS, 2010, p.65). De acordo com Gil (2008b, p.132), a entrevista estruturada é desenvolvida com base em uma relação de perguntas determinadas, no qual não é mudada a sequência e a escrita não é modificada, sendo a mesma para todos os sujeitos entrevistados. 
A aplicação das entrevistas realizadas se deu em período único, no mês de Julho (03/07 a 15/07/2015), e por meio do qual se obteve os dados para a elaboração deste trabalho. Considerou-se este período por ser o mais prático já que os professores estavam em férias escolares, e pelo fato de gerar menos desgaste, tanto para os sujeitos pesquisados quanto para o entrevistador.

Analisou-se primeiramente as respostas das entrevistas realizadas junto aos professores supervisores do PIBID-Química/FACEDI e posteriormente as respostas dadas pelos outros professores da escola que não atuavam no programa. Para se ter uma melhor organização da pesquisa e sua reflexão, as entrevistas foram divididas em categorias, o que vai aolçççç encontro com o pensamento de Gil (2002, p.134), de que a categorização fundamenta-se no arranjo de dados, em que é facilitado ao investigador tomar decisões e extrair suas conclusões. Ainda de acordo com Gil (2002, p.133) a análise é baseada em seguimento e atividades no qual é feito uma lapidação dos dados, os expressando em categorias, interpretando-os e fazendo as ressalvas necessárias.

As respostas das entrevistas realizadas com os professores supervisores que não foram bolsistas do PIBID e com os professores não atuantes no programas mas que participaram como bolsistas de Iniciação a docência, foram reunidas e divididas em três categorias: reflexões sobre o estágio e a formação docente, reflexões sobre o PIBID e sua importância na formação de novos professores e propostas de melhorias para o estágio supervisionado.

Durante a descrição e análise dos resultados foram omitidos os nomes dos sujeitos da pesquisa para preservar sua identidade. Para diferenciação das falas optou-se por utilizar as seguintes representações: aos professores que participaram do estágio e do PIBID como prática formativa usou-se o P1 e P2 e para os docentes que tiveram como formação prática docente apenas o estágio, S1 a S4. Segundo Marconi e Lakatos (2003, p.201) o anonimato favorece uma maior liberdade para a análise e reflexão sobre as respostas.

\section{RESULTADOS E DISCUSSÃO}

Como as respostas dadas pelos dois grupos de professores eram bastante semelhantes, durante a discussão que se segue, eles serão identificados apenas como professores entrevistados, mantendo sua identificação individual $S_{n}$ (para supervisor) e $P_{n}$ (para professor que não atua no PIBID) somente quando suas falas forem citadas ou quando se verificar a necessidade de se acentuar a opinião de um grupo de professores específicos.

\section{Categoria 01 - As limitações do Estágio Supervisionado para a formação docente}

Todos os professores entrevistados, demonstraram insatisfação com o período vivenciado por eles no estágio. Segundo eles, o estágio supervisionado obrigatório não foi suficiente para uma preparação pedagógica devido ao pouco tempo de vivência na escola. Além disso, o professor regente da escola não tinha tempo para se dedicar ao estagiário, ficando o acadêmico limitado e tendo que planejar e aplicar atividades por conta própria, trabalhando um conteúdo muitas vezes muito diferente do que os alunos já estavam aprendendo. Jardilino (2014, p.360) também tem relatado haver reclamações dos estagiários, devido ao fato de não serem totalmente apoiados na escola pelos gestores e professores. Além disso, alguns docentes que recebem o estagiário não oportunizam um maior espaço na sala de aula, o aluno limita-se apenas a uma observação e uma regência, ou seja, não conhece a rotina da escola.

Não conhece nem a realidade da escola, nem da sala de aula como o todo. De forma geral o estágio não foi suficiente, por que o tempo é muito curto (Professor-P1).

Outra questão levantada pelos supervisores é a forma como são conduzidos os estagiários para a sala de aula, pois segundo eles, os estagiários são encaminhados para as melhores turmas, e isso os impossibilita de conhecer turmas que podem desafiá-los enquanto professores. Tais posicionamentos demonstra o que diz Dantas (2013, p.90) que o estágio realizar-se de modo a não propiciar ao professor principiante uma vivência íntegra da sua ação profissional. Por isso o 
estágio na forma como tem sido realizado não contempla todas as necessidades da formação docente, deixando lacunas na preparação inicial dos futuros professores.

Então o estágio deixa muitas lacunas, não é o suficiente para preparar o aluno de licenciatura (Supervisor-S1).

E estas lacunas demonstradas pelo supervisor S1, que também reflete a visão dos demais colegas, mostra que não é dada a esses estagiários uma base sólida do que de fato é a docência. Oliveira e Barbosa (2013, p.157), observam que o estágio se ver rodeado por vários desafios, entre eles entender o espaço do acadêmico estagiário no ambiente de ensino. É preciso considerar que os professores que hoje recebem licenciandos em suas turmas, possam enquanto estagiário, terem tido um processo de ensino muito conflituoso em relação a inclusão dentro da rotina escolar de forma que não os foi possibilitado brechas para adentrarem a realidade da escola. Porém vê-se que atualmente os estagiários passam pelo mesmo problema, apesar de universidade e escola terem passado por um processo de evolução e ter havido inúmeros estudos e debates sobre formação docente do aluno da instituição superior.

Esta ausência de vivência adequada do estagiário na escola trás algumas consequências principalmente quando o aluno recém formado chega ao campo de trabalho, pois de acordo com Papi e Martins (2010, p.44), é nesse período inicial que o professor enfrenta e fica de frente com a realidade concreta da escola e com adversidades que pode não está preparado para encarar. Segundo os professores entrevistados, alguns docentes formados sofrem um choque inicial, encontram uma realidade diferente da que haviam contextualizado na universidade em seu período de formação e acabam sofrendo muito durante o período de adaptação a rotina escolar.

\section{Categoria 02 - Contribuições do PI BID a formação docente e as limitações do estágio}

O PIBID é percebido em meio aos professores entrevistados, como um programa que de fato torna mais ameno o ingresso do professor recém-formado na escola. Diante de suas falas, percebe-se que o docente que participou do PIBID, chega mais seguro a escola e pronto para os desafios da sala de aula, não sendo mais esta, um campo desconhecido. Para os entrevistados a prática didática é vista com superficialidade no estágio e mais profundamente com o PIBID.

Os professores disseram que o PIBID preenche lacunas deixadas pelo estágio, principalmente por possuir um maior tempo de vivência na escola. Segundo eles, o estágio prepara o acadêmico da licenciatura para dar aula e não para o campo de trabalho, assim ocorrem deficiências na formação. A preparação para a sala de aula é insuficiente em decorrência dessa pouca carga horária, o que é diferente do PIBID.

O PIBID faz a gente conhecer os projetos, saber como o professor deve ser capaz de agir, isso o estágio não proporciona (Professor-P2).

Ainda, segundo os entrevistados, o PIBID contribui para a formação docente inserindo de fato o aluno na realidade escolar, pois segundo Canan (2012, p.12) o PIBID dá suporte aos alunos de licenciatura a terem um contato com o cotidiano da escola brasileira, antes de adquirir o título de professor. É necessário para o futuro professor ter as máximas experiências no seu processo formativo e delas tirarem uma reflexão a respeito da sua profissão. O que também foi dito pelos entrevistados, pelos quais, no PIBID os estudantes da licenciatura tem a oportunidade de realmente se descobrirem e se decidirem pela docência.

Apesar de possuírem objetivos com fins comuns, essas duas práticas metodológicas se mostram segundo os supervisores, diferenciadas na forma como são desenvolvidas. Para eles o PIBID insere o aluno concretamente no ambiente de atuação, contempla um vasto campo de conhecimentos a serem aprendidos, ou seja, preenche sim as limitações deixadas pelo estágio.

A maior carga horária do bolsista na escola, o que não acontece no estágio, favorece o acompanhamento das atividades da escola como os planejamentos, e a rotina escolar. Além disso, o bolsista PIBID exercita mais momentos de observações e regências em sala de aula, o que é corroborado por Silva (2013, p.23) que afirma que apesar do PIBID ser opcional e o estágio obrigatório, há características próprias como o tempo de vivência que o aluno da licenciatura possui em sala de aula. 
Para os professores entrevistados, o PIBID se tornou importante para formação docente, por que o estágio não faz o acadêmico conhecer a realidade do seu campo de trabalho, o que pode ser percebido pela fala do professor S3 e os demais, pois segundo eles no PIBID o licenciando conhece os desafios da profissão, adquire um conhecimento didático melhor na forma de ensinar, além de ser propiciada uma formação no qual se aprende a lidar com os alunos da escola, a entendê-los, além é claro da formação na área de conhecimento específico.

O PIBID contempla um leque muito maior de possibilidades para o estudante, tanto para seguir a carreira docente como se interessar por outras funções dentro da escola. Acredito que o PIBID é amplamente contemplado nas atividades da escola (Professor supervisor S3).

Essas possibilidades de fato não são oportunizadas durante o estágio supervisionado. É o que diz Gama et al., (2013, p.1524) que o PIBID vem suprir as brechas que existem dentro dos cursos de Licenciatura. É o PIBID supre essa necessidade, de possibilitar ao aluno da graduação uma compreensão maior da rotina da escola e se preparar para ela. Corroborando com os professores entrevistados, Paredes e Guimarães (2012, p.276) relata em seu trabalho que o PIBID na visão dos professores supervisores é entendido como um avanço no processo formativo inicial, devido a vivência de forma mais contínua da realidade que cerca o ambiente escolar.

Para os supervisores, o PIBID é, portanto, uma oportunidade que deveria ser estendida a todos os alunos de graduação. O professor S2, afirma que se tivesse tido a chance de participar desse programa teria sido mais fácil a sua inserção na escola, pois esta participação amplia a visão e a reflexão sobre o ambiente escolar, pois segundo ele,

O PIBID eu considero algo mais completo para preparar o aluno para seguir a carreira de professor nas escolas (Professor superviso S2).

Observa-se ainda que os professores supervisores com unanimidade gostariam de ter tido a experiência de participar do PIBID, por que para eles o estágio não os preparou para exercer a profissão.

Já cheguei a comentar como eu gostaria de ter participado do PIBID, tem uma carga de informação e formação muito maior que o estágio, é porta de entrada larga, proporciona muitas possibilidades, ajuda bastante caso queira mesmo, caso não queira é uma oportunidade de descobrir isso, antes de ir de fato para a escola, você decide o que quer, se vai para a sala de aula ou não, já sabendo o que quer, faz você tomar decisões (Professor supervisor S3).

Para os professores que tiveram a oportunidade de terem sido bolsistas do programa, o PIBID contribuiu demais para a formação. Mediante o relato destes, o PIBID faz com que o aluno universitário, aluno de licenciatura, seja realmente inserido no mundo escolar. Na fala dos professores, o acadêmico vai refletir se ele quer ou não realmente ser professor e os prepara para os desafios que se possa encontrar na jornada docente. É possível enxergar a contribuição proporcionada por esse programa.

Só tenho a agradecer, me fez perceber como é importante ser professor, e ainda mais, me fez acreditar que o Brasil pode ter uma educação melhor, com esses programas e com essa preparação melhor de universitários (Professor-P1).

Percebe-se o quanto o programa atua significativamente no desenvolvimento dos novos professores e deixa rastros de uma vivência docente qualificada dos professores que já estão em atuação, criando nestes, novas perspectivas e uma razão para prosseguir na profissão. Para Rosa e Mattos (2013, p.161) o PIBID é um momento de relações, interação entre as diversas experiências e a constituição da identidade como professor, para os bolsistas do programa, e também para os docentes da educação básica.

\section{Categoria 03 - Contribuições do PIBID a propostas de melhorias no estágio supervisionado}

Os professores entrevistados também fizeram reflexões baseadas em como tem sido trabalhado os estágios supervisionados e como o PIBID tem contribuído para a formação docente, de forma 
a sugerir algumas propostas para melhoria do estágio supervisionado. Um dos pontos a ser considerado foi a remuneração dos professores que recebem alunos estagiários.

Como diz Jardilino (2014, p.360), os alunos da licenciatura, assim como os coordenadores responsáveis pelas áreas de atuação e os professores supervisores tem uma ajuda financeira para produzirem suas ações na escola. O que facilita e estimula a uma experiência prática da docência. Em contrapartida, ainda segundo Jardilino (2014, p.360), diferente do PIBID, no estágio, os professores que são responsáveis pela disciplina e os docentes da escola que recebem os estagiários não usufruem desse suporte financeiro para promoverem as atividades que são atribuídas ao estágio.

Percebeu-se que alguns dos supervisores concordam que a remuneração seria importante no estágio, mas para eles, a diminuição da carga horária dos professores que recebem o estagiário, num acordo entre universidade e escola seria o ponto mais importante a ser discutido. Pois segundo eles não é só a questão do dinheiro, é necessário que a escola disponibilize tempo, para que o professor possa orientar o aluno estagiário.

No entanto é preciso reconhecer que as possibilidades são pequenas, ele não tem tempo para aquilo, não é só má vontade do professor é por que o tempo é muito pequeno, mas com certeza seria um incentivo (o dinheiro) (Professor supervisor S4).

Então nota-se que a remuneração para esses professores, não é descartada, mas também não é a solução, pois ver-se segundo eles que para a melhor aproveitamento do estágio, o aumento da carga horária mediante a uma vivência assídua é uma das formas mais eficiente para a formação docente. Realmente o professor precisa de tempo para inserir o estagiário no contexto escolar, possibilitando a ele novos conhecimentos. Mas fica claro que o recurso financeiro proporcionado pelo PIBID faz diferença na realização das atividades, como fala Jardilino (2014, p.360) que os bolsistas se dispõem de um artifício financeiro para realizar suas ações dentro da escola, enquanto que os estagiários cumprem suas atividades de forma a exigir baixo ou nenhum custo.

Outra questão sugerida seria uma aproximação maior entre universidade e escola, de forma a permitir um diálogo entre gestão, os professores da escola e os professores da universidade sobre a importância do estágio e como ele deve ser trabalhado. Segundo eles essa discussão é necessária, pois a escola precisa proporcionar uma maior abertura para os alunos estagiários que a procuram e para os professores que os recebem, proporcionando mais espaço e um maior tempo, para que tenham mais liberdade de organizar e planejar as suas ações.

Conhecer realidades diversas é outra proposta. De acordo com Wiebusch e Ramos (2012, p.12), os acadêmicos no seu processo inicial precisam se defrontar com o exercício pedagógico nas escolas e em escolas variadas, fazendo com que haja a oportunidade de experiências e conhecimentos, saber como é comandar uma turma de alunos, assim como conhecer suas realidades diversas.

Um estágio mais diferenciado, com escolas diferentes, se no mesmo colégio, com professores diferentes, por que se o aluno se limita a uma observação e a uma regência, ele tem uma visão muito pequena. A questão da remuneração é uma boa opção também, muito mais para o estudante, por que muitas vezes o mesmo se sente desmotivado. Se o estágio se aproximasse um pouco do que é o PIBID, poderia também melhor capacitar esses professores (Supervisor-S2).

Os professores supervisores consideram que todo aluno do curso de licenciatura deveria participar do PIBID, mas eles priorizam que seoestágio fosse melhor vivenciado, e tivesse ações similares as do PIBID, já haveria um gigantesco salto de qualidade na formação dos futuros docentes.

O PIBID ele é tão encaixado na educação, penso que poderia ser incrementado no próprio estágio algumas ações que são realizadas no PIBID, e isso iria facilitar muito para os alunos. Não é criar mais uma disciplina dentro da universidade, mas acho que iria melhorar o estágio supervisionado, no qual daria uma ajuda, uma roupagem maior em relação a isso, algo melhor do que é atualmente. O PIBID ele é uma oportunidade grande de você ter essa formação profissional melhorada (Professor supervisor S3). 
Apesar do programa PIBID e os estágios procurarem contribuir para a formação do futuro professor, o tempo ou a carga-horária das atividades foram citados pelos professores como principal diferença entre PIBID e estágio. Para eles o estágio só insere o aluno na sala de aula e conhece vagamente a escola.

O PIBID ele insere de fato o aluno, é mais vivência na escola, participação nos eventos, nos projetos, planejamentos dos professores, faz acompanhamento com os alunos, sabe como agir, e assim faz com que o acadêmico chegue a escola realmente capaz (Professor-P2).

De acordo com Meinerz (2013, p.232) o PIBID propicia a criação de laços, entendidos enquanto ampliação de afinidades inovadoras entre docentes em início do processo formativo e docentes em atividade laboral, mediante inclusão diária nos tempos e espaços do âmbito escolar, edificando processos de maior curso e permanência.

\section{CONSI DERAÇÕES FINAIS}

Ficou claro que o estágio supervisionado no Curso de Química desenvolvido na FACEDI não tem conseguido inserir de fato os licenciandos na rotina escolar, ocasionando com que muitos desses, enfrentem dificuldades ainda maiores por não conhecerem concretamente o campo de trabalho, tendo esses professores na sua maioria um choque de realidade entre o que é visto na academia e o que é vivenciado na escola.

Conseguiu-se perceber que o PIBID é essencial para a formação docente dos alunos de Química da FACEDI/UECE pois o programa parece preencher brechas formativas deixadas pelo estágio, mas também percebeu-se que se for bem planejado, o estágio, com uma maior carga horária dentro da sala de aula e na escola, pode se assemelhar ao PIBID, pois ver-se que a maior diferença entre essas duas práticas está no tempo de vivência docente que é oportunizado ao aluno da licenciatura.

Viu-se a partir do trabalho realizado que o PIBID é importante para a formação dos novos professores do curso de Química da FACEDI/UECE. A pesquisa torna-se importante por que é necessário mostrar mediante posicionamento dos que já passaram pela FACEDI, o quanto o programa de iniciação à docência foi importante para a formação de quem dele participou e como teria favorecido aqueles que enquanto acadêmico não tiveram a oportunidade de participar.

O fato de ex-alunos terem analisado o período de estágio como insatisfatório na preparação, para a atuação em sala de aula, sugere o quanto é necessário que o curso de Licenciatura em Química FACEDI/UECE repense a maneira como é exercida essa prática docente tão importante para a formação de seus alunos de forma que o estágio forneça resultados formativos semelhantes aos obtidos com o PIBID.

Assim, este trabalho pretende contribuir para novas discussões sobre o estágio e sugerir ainda que haja um maior diálogo entre a escola e a academia no sentido de que juntas possam compreender o estágio como um período de grande importância para a formação dos futuros professores assim como o PIBID na opinião dos entrevistados tem sido.

\section{REFERÊNCI AS}

CANAN, S.R. Política nacional de formação de professores: um estudo do PIBID enquanto política de promoção e valorização da formação docente. IX ANPED SUL - Seminário de pesquisa da região Sul. URI,2012.

DANTAS, L.K. Iniciação à docência na UFMT: contribuições do PIBID na formação de professores de química. CUIABÁ - MT, 2013. 
GAMA, A. G. B; JÚNIOR, E. B. M; BARBOSA, E. M; NETO, F. P. S; TARGINO, K. C. F.; SOUZA, M. C. M; FERNANDES P. R. N. A importância do projeto PIBID na formação dos alunos de Licenciatura em Química do IFRN Campus - APODI. IX CONGIC. Congresso de Iniciação Científica. Julho/ 2013.

GIL, A.C. Como elaborar projetos de pesquisa. 4. Ed. - São Paulo: Atlas, 2002.

Como elaborar projetos de pesquisa. 4. ed. São Paulo: Atlas, 2008a.

Métodos e técnicas de pesquisa social. 6. ed. São Paulo: Atlas, 2008b.

JARDILINO, J.R.L. Políticas de formação de professores em conflito com o currículo: estágio supervisionado e PIBID. Educação | Santa Maria | v. 39 | n. 2 | p. 353-366 | maio/ago, 2014.

KAUARK, F.S; MANHÃES, F.C; MEDEIROS, C.H. Metodologia da pesquisa: um guia prático. Itabuna: Via Litterarum, 2010.

MARCONI, M.A; LAKATOS, E.M. Fundamentos da Metodologia Cientifica. 5. Ed. São Paulo: Atlas, 2003.

MEINERZ, C.B. Estágios de docência e PIBID: impactos inimagináveis no campo do Ensino de História. Revista Latino-Americana de História. Vol. 2, nº 6 - Agosto de 2013 Edição Especial.

OLIVEIRA, A; BARBOSA, V.S.L. Formação de professores em ciências sociais: Desafios e possibilidades a partir do Estágio e do PIBID. Revista Eletrônica Inter-Legere (ISSN 19821662) Número 13, Julho/Dezembro, 2013.

PAPI, S.O. G; MARTINS, P.L.O. As pesquisas sobre professores iniciantes: algumas aproximações. Educação em Revista | Belo Horizonte | v.26 | n.03 | p.39-56 | Dez., 2010.

PAREDES, G.G. O; GUIMARÃES, O.M. Compreensões e Significados sobre o PIBID para a Melhoria da Formação de Professores de Biologia, Física e Química. Química Nova na Escola, Vol. 34, N 4, p. 266-277, Novembro, 2012.

ROSA, K.S; MATTOS, L. Tem gente nova na escola: os benefícios do PIBID para o espaço escolar. Revista Veras, São Paulo, v. 3, n. 2, p. 160-173, Julho/Dezembro, 2013.

SILVA, K.D. PIBID x ESTÁGIO OBRIGATÓRIO: A IMPORTÂNCIA DA PESQUISAAÇÃO. Brasília - DF, 2013.

WIEBUSCH, A; RAMOS, N.V. As repercussões do PIBID na formação inicial de professores. IX ANPED SUL - Seminário de pesquisa da região Sul, 2012.

XAVIER, J.P.B. O Estágio supervisionado no curso de licenciatura em língua inglesa em uma instituição de ensino superior na cidade de Paranaguá. IX Congresso Nacional de Educação - EDUCERE. Outubro, 2009. 